\title{
Hepatic actinomycosis with infiltration of the diaphragm and right lung: A case report
}

\author{
Tasbirul Islam MD MRCPUK, Muhammad Nauman Athar MD, Muhammad Kamran Athar MD, \\ Mohammed Haris Umer Usman MD, Baqir Misbah MD
}

T Islam, MN Athar, MK Athar, MHU Usman, B Misbah. Hepatic actinomycosis with infiltration of the diaphragm and right lung: A case report. Can Respir J 2005;12(6):336-337.

\begin{abstract}
Actinomycosis is an indolent, slowly progressive infection caused by anaerobic or microaerophilic bacteria of the genus Actinomyces. Actinomycosis has a myriad of clinical presentations, inducing both a suppurative and granulomatous inflammatory response. The infection spreads contiguously through anatomical barriers and frequently forms external sinuses. The most common clinical presentations are cervicofacial, thoracic, abdominal and, in females, genital. Classic features include purulent foci surrounded by dense fibrosis that, over time, cross natural boundaries into contiguous structures, with the formation of fistulas and sinus tracts in some cases. Hepatic actinomycosis presents as single or multiple abscesses or masses. Reported here is the unusual occurrence of actinomycosis of the liver involving the diaphragm and right lung. The present case illustrates the difficulties in diagnosing this rare and unrecognized disease.
\end{abstract}

Key Words: Actinomycosis; Hepatic abscess; Sulfur granules

\section{Une actinomycose hépatique avec infiltration du diaphragme et du poumon droit : Un rapport de cas}

L'actinomycose est une infection indolore peu évolutive causée par des bactéries anaérobiques ou microaérophiles du genre Actinomyces. Elle s'accompagne d'une kyrielle de présentations cliniques, qui induisent à la fois une réaction suppurative et une réaction inflammatoire granulomateuse. L'infection se propage aux structures contiguës à travers les barrières anatomiques et forme souvent des sinus externes. Les présentations cliniques les plus courantes sont de nature cervicofaciale, thoracique, abdominale et, chez les femmes, génitale. Les caractéristiques classiques incluent des foyers purulents entourés d'une fibrose dense qui, au fil du temps, traversent les barrières naturelles pour atteindre les structures contiguës et s'accompagnent parfois de la formation de fistules ou de voies sinusales. L'actinomycose hépatique se présente sous forme d'abcès ou de masses uniques ou multiples. Est exposée aux présentes l'occurrence inhabituelle d'une actinomycose hépatique touchant le diaphragme et le poumon droit. Ce cas démontre les difficultés diagnostiques reliées à cette maladie rare et peu connue.

\begin{abstract}
A n 84-year-old woman with a past medical history significant for hyperlipidemia and hypertension presented with one month of anorexia, right upper quadrant pain, nausea, night sweats and a weight loss of $5.9 \mathrm{~kg}$ over three months. One week before presentation she developed a cough with purulent sputum production and occasional streaks of blood. She was a nonsmoker and her surgical history was significant for a cholecystectomy five years ago.

Physical examination revealed a thin woman with no respiratory distress. Vital signs were stable and auscultation of the chest revealed crackles over the right lower posterior hemithorax. There was tenderness in the right upper quadrant of the abdomen, with hypoactive bowel sounds and no peritoneal signs. There were no palpable masses or hepatosplenomegaly; the remainder of the physical examination was normal.

Laboratory tests revealed a white blood cell count of $21 \times 10^{9} / \mathrm{L}$ (differential of $72 \%$ granulocytes, 16\% lymphocytes, $8 \%$ monocytes and $4 \%$ bands), an aspartate aminotransferase level of $199 \mathrm{U} / \mathrm{L}$ (normal $14 \mathrm{U} / \mathrm{L}$ to $48 \mathrm{U} / \mathrm{L}$ ), an alanine aminotransferase level of $89 \mathrm{U} / \mathrm{L}$ (normal $8 \mathrm{U} / \mathrm{L}$ to $50 \mathrm{U} / \mathrm{L}$ ), an alkaline phosphatase level of $123 \mathrm{U} / \mathrm{L}$ (normal $40 \mathrm{U} / \mathrm{L}$ to $120 \mathrm{U} / \mathrm{L}$ ) and a serum bilirubin level of $30.78 \mu \mathrm{mol} / \mathrm{L}$ (normal $0 \mu \mathrm{mol} / \mathrm{L}$ to $22 \mu \mathrm{mol} / \mathrm{L}$ ). The total protein and gamma glutamyl transferase levels were normal, as were the remainder of the routine laboratory tests. A chest radiograph at the time of admission (Figure 1) showed a cavitary lesion present in the right lower lobe. A computed tomography (CT) scan of the chest (Figure 2) showed multiple
\end{abstract}

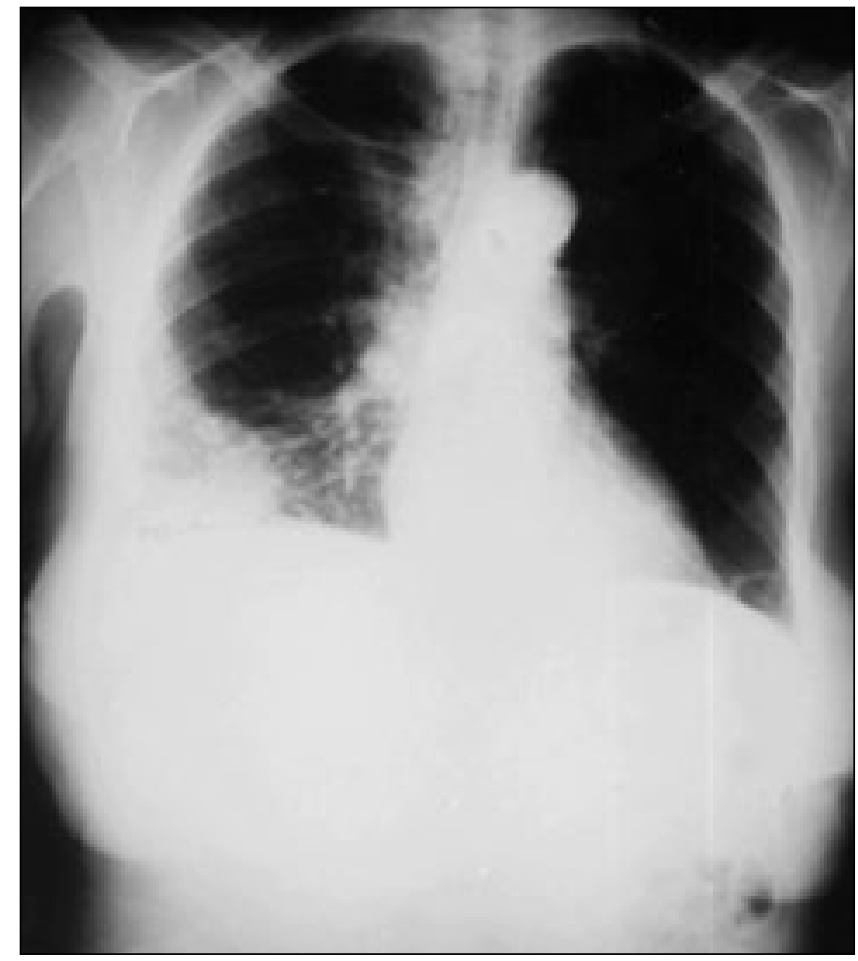

Figure 1) A posteroanterior chest radiograph taken at the time of admission showing a cavitary lesion in the right lower lobe 


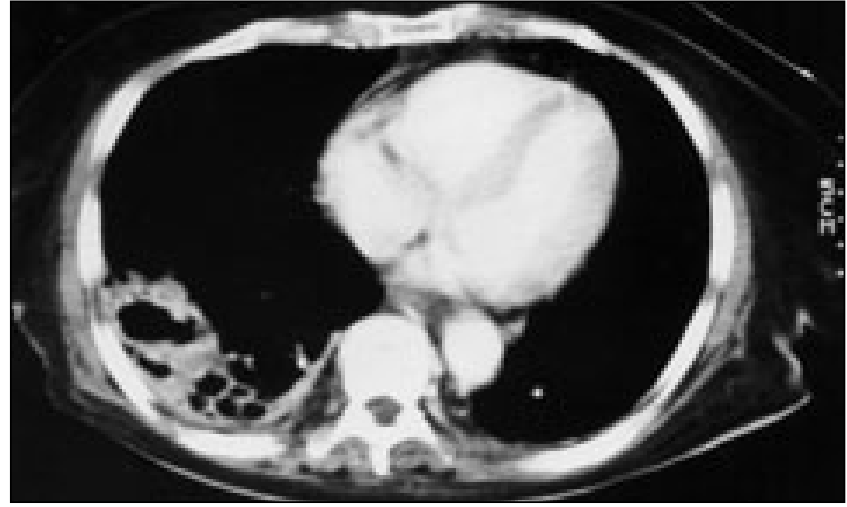

Figure 2) Computed tomography of the chest showing multiple thickwalled cavitary lesions in the right lower lobe with associated pleural thickening

thick-walled cavitary lesions in the right lower lobe with associated pleural thickening. A CT scan of the abdomen (Figure 3) showed a complex, septated fluid collection involving the liver with dense inhomogeneous contrast enhancement in the walls and extending into the posterior pararenal space.

CT-guided transthoracic needle aspiration revealed purulent material. A Gram stain of the fluid showed many white blood cells and Gram-positive, filamentous, branching organisms. Aerobic, anaerobic, fungal and tuberculous cultures were negative, as were modified acid-fast smears. The diagnosis was hepatic actinomycosis with involvement of the diaphragm and ipsilateral lung. The patient received penicillin therapy and demonstrated complete clinical and radiographical resolution.

\section{DISCUSSION}

The actinomycete are anaerobic or microaerophilic, nonsporeforming, Gram-positive, branching bacteria that colonize the mouth, colon and female genital tract. Six of the 13 Actinomyces species have been associated with human disease; of those, Actinomyces israelii is the most frequently isolated. The most common site of actinomycotic infection is the cervicofacial area, but pulmonary and hepatic abscesses are also encountered (1). Due to the fastidious nature of this organism, the culturing of Actinomyces species can be difficult, and the diagnosis is often based solely on the characteristic microscopic pathology (filamentous, branching and often beaded Gram-positive rods) (2). Nocardia species have a similar appearance when Gram stained; however, they can be differentiated from the actinomycete by a positive modified acid-fast stain.

The diagnosis of actinomycosis is often delayed, probably because of its subacute presentation. The presence of sulfur granules in exudates is strongly supportive of the diagnosis of actinomycosis; however, sulfur granules are less often detected when the specimens are retrieved via percutaneous aspirations (3).

Actinomycosis of the liver represents 5\% of all cases and 15\% of those cases involving the abdomen (4). Infection is frequently cryptogenic $(80.7 \%)$, presenting with fever $(83.3 \%)$, abdominal pain $(74.5 \%)$ and weight loss $(50.9 \%)$ over a $3.7 \pm 5.1$ month period. The most common radiographical finding is a single hypodense mass/abscess (68.4\%). Extension to surrounding tissues has been evident in 19 cases (33.3\%) (5). In Japan, Sugano et al (6) reviewed 11 cases of Actinomyces infection involving the liver. In most patients, there were no predisposing factors. Common symptoms and laboratory findings include

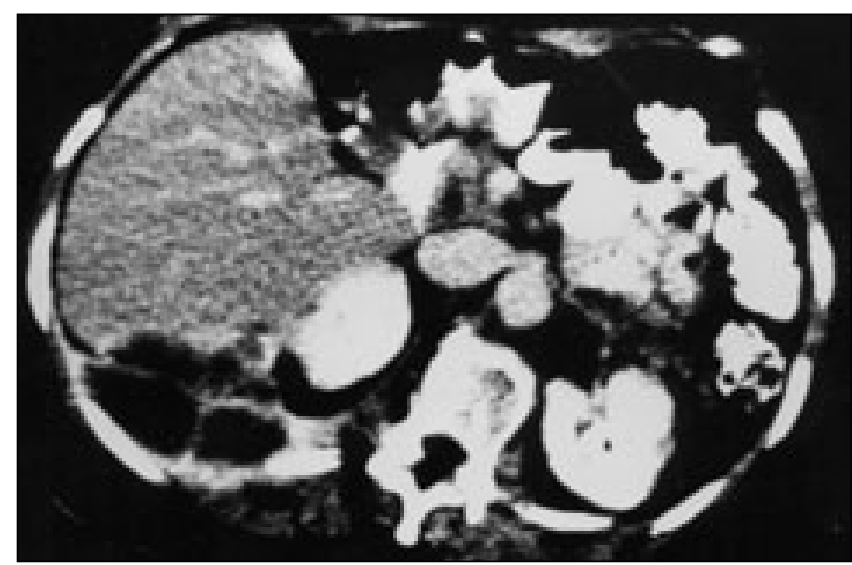

Figure 3) Computed tomography of the abdomen showing a complex, septated fluid collection with a thick, irregular, contrast enhancement in the wall involving the liver and extending into the posterior pararenal space

fever, abdominal pain, leukocytosis and elevated C-reactive protein. In six of the 11 patients, a partial hepatectomy was performed because hepatic tumour was suspected. Five patients presented with a liver abscess. Hepatic actinomycosis should be considered in the differential diagnoses of pyogenic liver abscess and space-occupying lesions of the liver (6). Prior abdominal surgery, as well as other disorders that cause a breach of the gastrointestinal tract mucosa, are recognized as risk factors for developing abdominal actinomycosis (1) Hematogenous dissemination occurs frequently from thoracic sites, but rarely from other areas (1). Hepatic abscesses are known to spread to the pleural space; however, direct involvement of the diaphragm and lung is less common (4). Given our patient's prolonged abdominal symptoms associated with a previously normal chest radiograph, we suspect that she had direct transdiaphragmatic infection of the lung from a primary infected hepatic site. To our knowledge, only one case report has documented direct invasion of the diaphragm and lung from a primary hepatic infection (4). CT findings confirmed the infiltrative nature of the disease, showing its tendency to invade across tissue planes and boundaries (7).

It is well established that actinomycosis often eludes diagnosis, even among the most seasoned clinicians. The infection can be indolent, and obtaining a definitive diagnosis can take up to years (1). Although speculative, it is interesting to conjecture whether this patient's infection was related to the cholecystectomy performed five years before presentation.

\section{REFERENCES}

1. Hoeprich PD, Jordan MC, Ronald AR. Infectious Diseases, 5th edn. Philadelphia: JB Lippincott Company, 1994:493-7.

2. Miyamoto MI, Fang FC. Pyogenic liver abscess involving Actinomyces: Case report and review. Clin Infect Dis 1993;16:303-9.

3. Jonas RB, Brasitus TA, Chowdhury L. Actinomycotic liver abscess. Case report and literature review. Dig Dis Sci 1987;32:1435-7.

4. Kasano Y, Tanimura H, Yamaue H, Hayashido M, Umano Y. Hepatic actinomycosis infiltrating the diaphragm and right lung. Am J Gastroenterol 1996;91:2418-20.

5. Sharma M, Briski LE, Khatib R. Hepatic actinomycosis: An overview of salient features and outcome of therapy. Scand J Infect Dis 2002;34:386-91.

6. Sugano S, Matuda T, Suzuki T, et al. Hepatic actinomycosis: Case report and review of the literature in Japan. J Gastroenterol 1997;32:672-6.

7. Ha HK, Lee HJ, Kim H, et al. Abdominal actinomycosis:

CT findings in 10 patients. AJR Am J Roentgenolog 1993;161:791-4. 


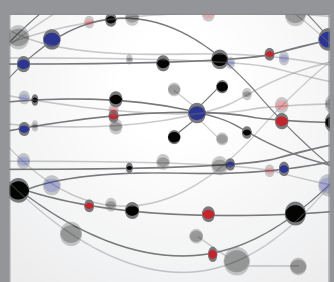

The Scientific World Journal
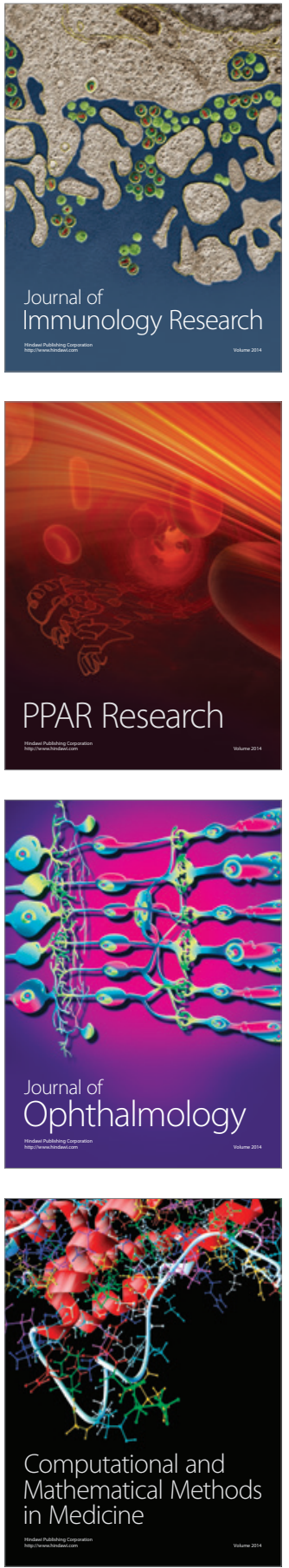

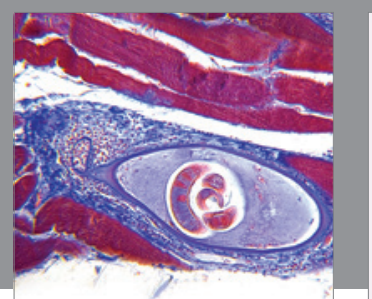

Gastroenterology Research and Practice

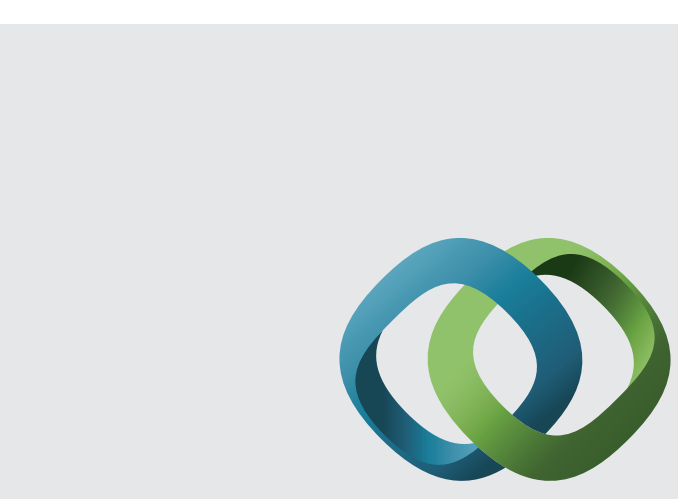

\section{Hindawi}

Submit your manuscripts at

http://www.hindawi.com
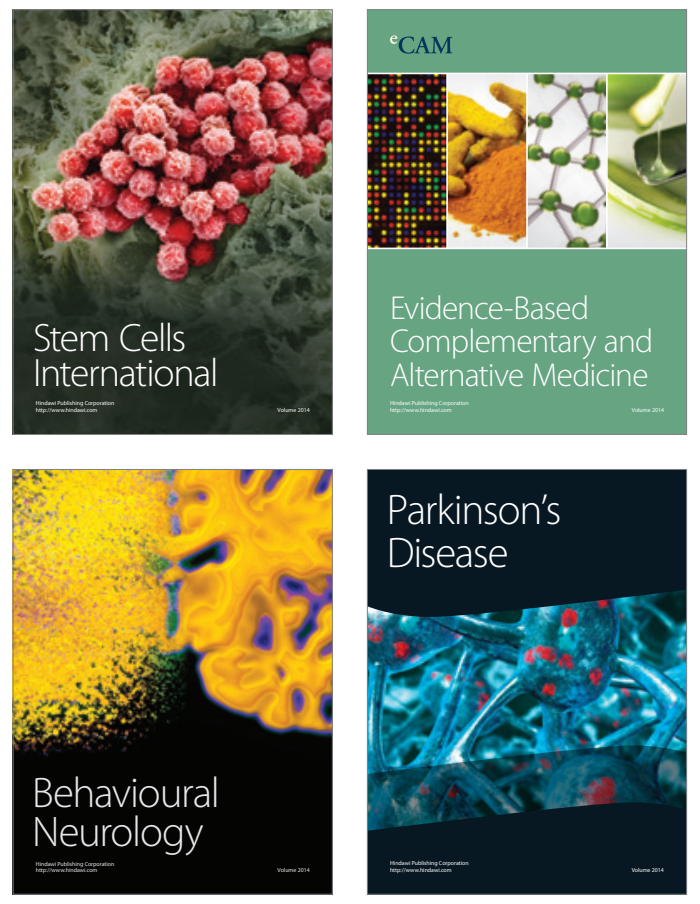
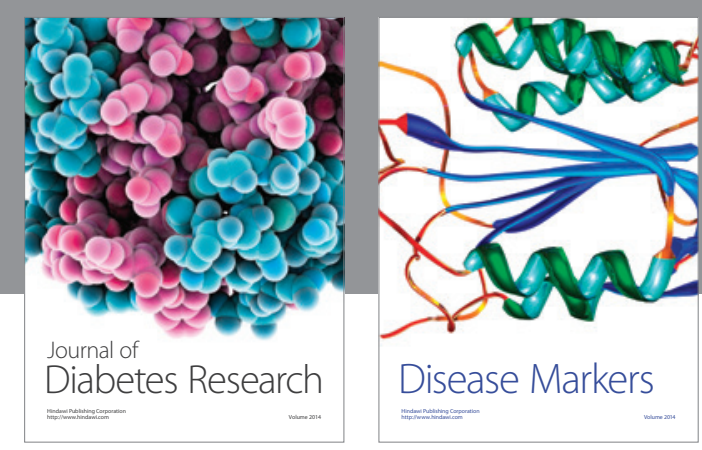

Disease Markers
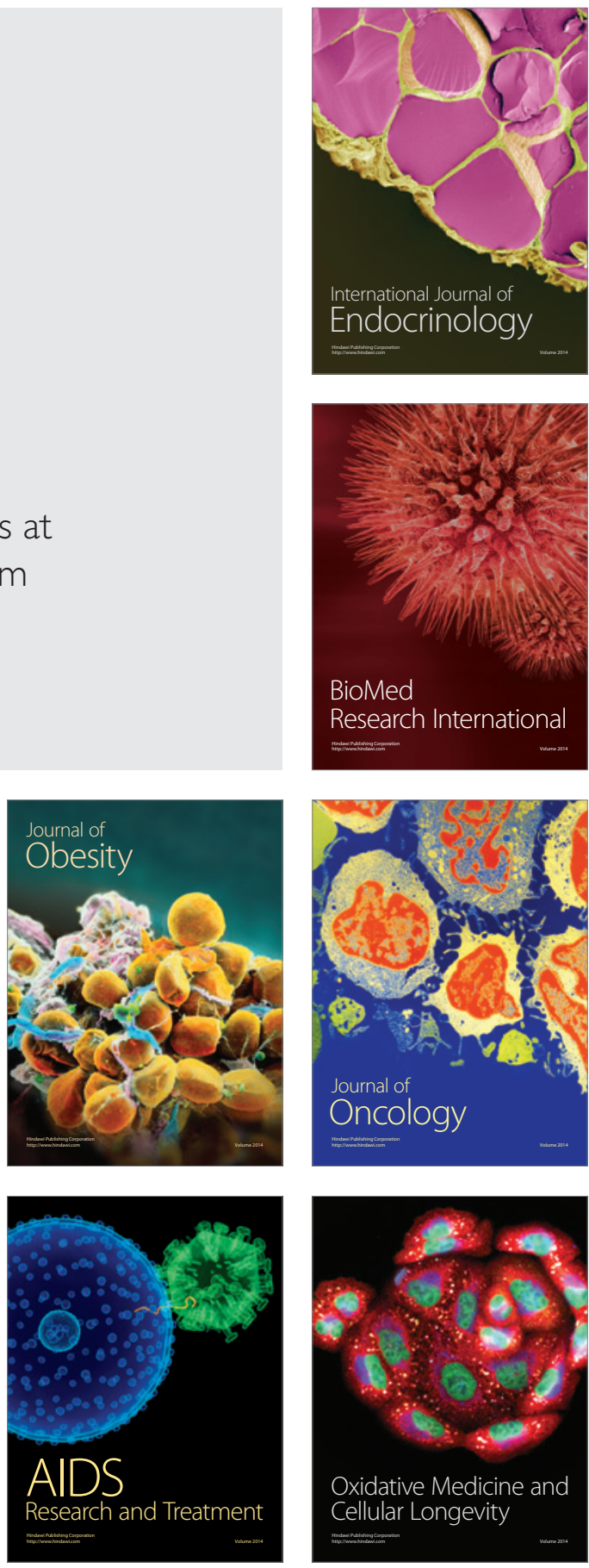